\title{
Macroeconomic Research, Present and Past
}

\author{
P.J. Glandon, Ken Kuttner, Sandeep Mazumder, Caleb Stroup*
}

July 2,2019

\begin{abstract}
What is the state of macroeconomics? We answer this question by hand collecting information about the epistemological approaches, theoretical and empirical methods, and data sources used by macroeconomists in their research. During the past 40 years there has been an increasing reliance on mathematical theory, particularly DSGE models, with theory-based papers now occupying the majority of space in macro journals. This shift is mirrored by a decline in the use of empirical falsification methods testing theoretical predictions. Microeconometric techniques have displaced time series methods, and empirical papers increasingly rely on micro and proprietary data sources. We document a decline and subsequent resurgence of financial frictions appearing in macro theory. Finally, we find that topics outside of macroeconomics are studied in more than three fourths of macro field journal publications.
\end{abstract}

JEL Classification: A11, A14, B22, E00, O30

Keywords: macroeconomics, methods, research, macroeconomic publications

\footnotetext{
${ }^{*}$ Glandon: Kenyon College (glandonp@kenyon.edu). Kuttner: Williams College and NBER (knk1@williams.edu). Mazumder: Wake Forest University (mazumds@wfu.edu). Stroup: Davidson College (castroup@davidson.edu). We thank Esteban Argudo, Daniel Hamermesh, Anton Korinek, Greg Phelan, Tim Taylor, and seminar participants at Kobe University, the 2018 Conference of Macroeconomists from Liberal Arts Colleges, and the 2018 meeting of the Southern Economic Association for helpful comments.
} 


\section{Introduction}

This paper uses data on the characteristics of over 1,200 journal articles published in the past four decades to take stock of the state of macroeconomic research. Our aims are to document the range of methods and topics encountered in the recent literature, and to describe some of the ways in which macro research has changed over time. Our analysis allows us to address some oft-heard critiques of the field, such as an over-reliance on stochastic general equilibrium (DSGE) models, insularity, or inattention to the financial sector.

Section 2 explains the methodological attributes used in our analysis. One set of attributes characterizes the underlying research epistemology, focusing specifically on the extent to which data are used to either refute or support the implications of economic theory. The second set pertains to the theoretical framework, e.g. partial versus general equilibrium, and the particular style of DSGE modeling. The third set describes the nature of the empirical analysis, distinguishing papers using conventional time series methods from those using microdata and methods borrowed from applied micro research.

We also identify two attributes relating to research topics. First, we identify papers that incorporate financial frictions, which allows us to speak to Stiglitz's (2018) critique that macroeconomists have ignored the financial sector. Second, to characterize the diversity of topics within macro and cross-fertilization between macro and other fields, we tabulate the frequency with which papers in traditional macroeconomics categories include other JEL codes.

Using these categories as a guide, we hand-collected key attributes of 1,247 articles published in eight journals over a 38-year period. Our dataset includes 1,153 articles from five macro field journals: the Journal of Monetary Economics, the Journal of Economic Dynamics and Control, the Journal of Money, Credit and Banking the American Economic Journal: Macroeconomics, and the Review of Economic Dynamics. Also included are 94 macro articles (designated by JEL code "E") published in 2016 and 2017 from three leading general-interest journals: the American Economic Review, the Quarterly Journal of Economics and the Review of Economic Studies. Section 3 describes our dataset in greater detail.

Section 4 reports our results. The first main finding is that macroeconomic research has become increasingly theoretical. Two-thirds of current macro research is theory-based, compared with less than $40 \%$ in 1980. This trend towards theory is largely due to the growing popularity of quantitative DSGE models. DSGE analysis went from being practically nonexistent in 1990 to accounting for over half of theory articles by 2017. The share of 
theory-based articles employing partial equilibrium analysis has been falling steadily since 1980, displaced by static general equilibrium (GE) and later by DSGE methods.

Second, the trend towards theory-based research has been accompanied by a steady decline in research emphasizing falsification, with only $25 \%$ of articles currently falling into that category. The current emphasis on theory in macroeconomic research is less pronounced in general interest journals relative to field journals, however.

Third, there has been a dramatic change in the empirical methods and data used in macroeconomic research. Especially noteworthy is the steep increase in the use of micro datasets and empirical techniques borrowed from applied microeconomics. This rise in microbased techniques is associated with a marked decline in the use of time series methods, and today fewer than half of published empirical papers rely primarily on time series analysis.

Fourth, macroeconomists' attention to the financial sector has varied a great deal in the past four decades. Finance figured prominently in macro research in the early 1980s, when $40 \%$ of theory papers included a substantive role for financial markets or institutions. Interest waned in the 1980s and 1990s, and by 2000 only $10 \%$ included any sort of financial friction. The trend reversed itself in the mid-2000s, and the share of papers addressing financial sector issues increased sharply following the financial crisis.

Fifth, research published in macroeconomics journals relates to wide range of other fields. Macro journals publish a large number of articles that list JEL codes from other major fields within economics. Similarly, more than three-quarters of macro (E-designated) papers list at least one field from outside of macro.

Our overall conclusion, summarized in section 5 , is that macroeconomics is a diverse and evolving field. Despite the ascendance of New Keynesian DSGEs, a wide variety of other modeling frameworks remain in extensive use. Macroeconomists have responded to the longstanding challenge of identifying causal relationships with greater reliance on theory, a shift in emphasis from testing to fitting models, and the creative use of micro-based identification strategies. And far from being insular, there is considerable overlap between macroeconomics and other fields.

\section{A taxonomy of approaches and methods}

This section explains the classification system we use to characterize macroeconomic research. The scheme, summarized in Table 1, is based on three broad features. The first has to do with the underlying epistemology. The second concerns the characteristics of the theory used 
(if any). The third encompasses the type of data and empirical methods used (if any).

\section{$2.1 \quad$ Epistemology}

First, we classify papers according to epistemology, a term we use to describe the nature of the question posed and the type of reasoning used to substantiate the conclusions. Using the criteria discussed below, we assign papers to one of four categories based on the relationship between theory and data: whether, and how, data are brought to bear on theory; and the degree to which theory informs the empirical analysis, if at all. A number of examples are enumerated in Table 2.

Description. The objective of papers in this category is to document facts or highlight features of the data, without imposing a theoretical structure or testing any theory-based hypotheses. Research of this type generally involves the use of plots, correlations, reducedform regressions, or narrative accounts, to characterize patterns in the data. A paper might use these methods to to assess the procyclicality of inflation, for example.

Pure theory. These papers use mathematical deduction to formally derive conclusions from a set of assumptions. ${ }^{1}$ Plausible parameter values may be assigned for illustrative purposes, and numerical methods may be used to solve the model; but parameter values are not chosen to make the model fit the data. A mathematical model incorporating price stickiness could be used to make theoretical predictions regarding the cyclicality of inflation, for example.

Falsification. The purpose of this type of research is to subject a theory to empirical testing. This is consistent with Karl Popper's philosophy of critical rationalism, which holds that empirical falsification is essential to the scientific method. ${ }^{2}$ Most falsification exercises employ conventional econometric methods to estimate a model's parameters. Testable theoretical implications are expressed in terms of restrictions on one or more of the parameters. For example, a paper in this category might test the null hypothesis that unemployment has no effect on inflation, against the alternative Phillips Curve hypothesis that low unemployment causes inflation to rise.

Quantitative modeling methods are occasionally used in falsification exercises. Although the method is not amenable to formal statistical hypothesis tests, it is possible to compare

\footnotetext{
${ }^{1}$ In principle, pure theory need not entail mathematics - Smith and Ricardo expressed their theories entirely in prose, after all - but that has become exceedingly rare.

${ }^{2}$ This is echoed in Friedman (1946): " [T] he ultimate test of the validity of a theory [is] the ability to deduce facts that have not yet been observed, that are capable of being contradicted by observation, and that subsequent observation does not contradict.
} 
the model's predictions with the data; those whose predictions are contradicted by the data, either generically, or for a plausible set of parameter values, would be rejected. For example, a paper might demonstrate that a certain class of DSGE models delivers countercyclical inflation, whereas inflation is procyclical in the data.

Papers exhibit varying degrees of falsifiability. On one end of the spectrum, research that confronts a fully articulated model with data, setting up the possibility of rejecting one or more of its elements, clearly qualifies as falsifiable. On the other end of the spectrum is research that focuses on measurement, rather than the outright acceptance or rejection of a model; although often implicit in the exercise is a null hypothesis corresponding to a special case or constrained version of the model. Just-identified Structural Vector Autoregressions (SVARs) lie closer to the measurement end of the spectrum, since they are typically more concerned with quantifying the contribution of an effect (e.g. the response of inflation to monetary policy shocks) rather than testing a specific hypothesis, beyond the null of a nonzero effect. We also put these in the falsification bin, despite the limited scope of the exercise.

Model fitting. This style of research takes as given a theory derived from a priori reasoning and chooses parameter values to mimic selected features of the data. ${ }^{3}$ This approach is most commonly associated with DSGEs, but it is sometimes used with other types of models. Korinek (2017) summarizes the "recipe" for this style of research as follows:

- to establish "stylized facts" about the quantitative interrelationships of certain macroeconomic variables (e.g. moments of the data such as variances, autocorrelations, covariances, ... ) that have hitherto not been jointly explained;

- to write down a DSGE model of an economy subject to a defined set of shocks that aims to capture the described interrelationships; and

- to show that the model can "replicate" or "match" the chosen moments when it is fed with stochastic shocks generated by the assumed shock process.

For example, a paper might introduce a new type of stickiness in an effort to better match the observed correlation between inflation and the unemployment rate. An exercise of this type could also be used to quantify the welfare gains (or losses) of a policy to reduce unemployment.

\footnotetext{
${ }^{3}$ This approach is associated with Adelman and Adelman (1959), who proposed using a "goodness-ofmimicry" criterion to evaluate large-scale Keynesian-style structural econometric models.
} 
Many papers performing moment-matching exercises also perform econometric analysis. We classify these papers according to our judgement of the paper's primary contribution. For example, a paper that used econometric results to document a "stylized fact" for the model to "explain" would be classified as a model fitting exercise.

\subsection{Attributes of pure theory and quantitative models}

Next, we classify those papers with a theoretical emphasis according to the following four sets of attributes. Table 3 provides a number of examples.

Equilibrium concept. A paper's scope of equilibrium can be partial equilibrium (PE), general equilibrium (GE), or dynamic stochastic general equilibrium (DSGE). We include in the DSGE category all equilibrium business cycle models, not just those of the New Keynesian variety. The article is categorized as DSGE if in addition to being a general equilibrium model, it contains one or more random processes and the analysis of the model focuses on deviations from the steady state or trend.

Calibration versus optimization. The majority of papers using quantitative macro models are calibration exercises. This generally involves using "off-the-shelf" parameters taken from other sources, with a subset often obtained from conventional econometric methods and reported in the paper. Analyses of this type have the flavor of the "quantitative experiment" methodology described by Kydland and Prescott (1996). In others, the models' parameters are jointly optimized to match a large number of moments as closely as possible; these exercises are more akin to the Sims (1996) "data compression" philosophy. ${ }^{4}$ Many papers in the quantitative models bin use some combination of calibration and optimization methods, but we classify as optimized papers in which most model parameters are fitted to the data.

Financial frictions. In order to assess the critique that macroeconomics has ignored finance, we identify papers in which the financial system and/or financial frictions play a substantive role. ${ }^{5}$ Specifically, we count as incorporating the financial sector those theory papers that examine financial frictions such as collateral constraints or costly default, as well as those that explicitly study the behavior of or interactions among financial intermediaries.

$D S G E$ genres. DSGEs share a number of common features. By definition, all are dynamic, incorporate random shocks, and include an aggregate resource constraint. All have microfoundations and most incorporate a consumption Euler equation. There are many

\footnotetext{
${ }^{4}$ We use the term "optimized" instead of "estimated" to distinguish the procedure from conventional econometric methods.

${ }^{5}$ In the same spirit, Reis (2018) examines general interest journals and counts the number of papers that self-report JEL classifications E and F (macroeconomics and financial economics).
} 
different genres, however. We identify seven, based on the following distinguishing features:

- Real Business Cycle (RBC) models include capital as a state variable. Markets clear. Technology shocks are the primary source of fluctuations.

- Monetary models include the money supply in such a way as to make it non-neutral in the short run. Modeling strategies include cash-in-advance constraints, shopping costs, and money in the utility function.

- New Keynesian (NK) models include price and/or wage stickiness, typically (but not exclusively) based on the Calvo (1983) specification. Monetary policy is based on an interest rate; the money supply plays no role.

- Search and matching models use frictions other than wage stickiness (e.g. search costs), to generate unemployment. Shocks may originate from a number of different sources, including productivity, monetary policy and government purchases.

- OLG/life-cycle models are those in which agents' saving behavior is determined by age or generation.

- Stochastic growth models are similar to RBCs in their emphasis on market clearing and capital accumulation, but consider the longer-term impact of regime changes (e.g. changes in tax rates).

- Trade-based DSGEs include trade between two or more countries, and incorporate features from conventional trade models, such as comparative advantage. Shocks may originate from a number of different sources, including productivity, monetary policy and government purchases. Open-economy models with NK features (sticky prices, interest rate rules) are classified as New Keynesian, rather than trade.

Papers with models that do not fit into any of these categories are put into an "other" bin.

\subsection{Econometric approaches and dataset attributes}

For papers in the descriptive or falsification categories, we define two broad categories of econometric approach, and document five features of the data used in the analysis. Table 4 provides a number of examples.

The two econometric approaches are as follows: 
- Time series versus applied microeconomic methods. Papers based on time series methods use estimators with large- $T$ asymptotic properties (many observations indexed by time, including panel time series models). Papers using applied microeconomic techniques rely on estimators with large- $N$ asymptotic properties (many cross-sectional units, including conventional panel data).

- Reduced-form, structural and experimentalist models (only for papers in the applied micro category). Reduced-form empirical specifications are those which do not deliver explicit estimates of structural parameters (e.g. the frequency of price setting in a sticky-price model or the intertemporal elasticity of substitution). A model is classified as structural if at least one parameter has such an interpretation. Papers using experimentalist methods frame the exercise as a quasi- or natural experiment, and use techniques (e.g. diff-in-diff and regression discontinuity) that have been developed to compare differences between "treatment" and "control" groups.

The five dataset attributes are as follows:

- Data structure. We classify papers according to whether they use cross-sectional ("indexed by $i$ "), time series ("indexed by $t$ ") or panel ("indexed by $i$ and $t$ ) data.

- Unit of observation. This refers to the entity (country, state, MSA, industry, asset, product, firm, subsidiary, household, individual) for which the data are observed.

- Microdata. Papers using microdata are those in which the unit of observation corresponds to an individual decision maker (a person, household, establishment, subsidiary, or firm), or to an individual asset or product. This excludes papers based on geographical or political unit (e.g. countries, states, MSAs). The designation only applies to papers using cross-sectional or panel data and employing applied micro methods.

- Frequency. The frequency refers to the period associated with the time index (annual, quarterly, monthly, weekly, daily, or intra-day). The designation only applies to papers using panel and time series data.

- Proprietary. A paper is tagged as using proprietary data if it uses data that are not freely available. This includes data purchased from commercial providers (e.g. Compustat), those with restricted access (e.g. Census microdata), data used by special permission (e.g. regulatory or internal firm data), or collected by the researcher (e.g. field experiments, lab experiments or surveys). 


\section{Data}

We perform two complementary analyses. One is an assessment of the current state of macroeconomic research based on a cross section of macro articles from 2016 and 2017. The second uses a longitudinal dataset of articles from 1980 through 2017 to characterize research trends. Determining exactly what constitutes a "macro" article is not straightforward, however, given the diversity of current research. We use two alternative criteria for making this determination.

One criterion is to include all of the articles published in five leading macroeconomics journals: Journal of Monetary Economics (JME), Journal of Money, Credit and Banking (JMCB), American Economic Journal: Macroeconomics (AEJ), Journal of Economic Dynamics and Control (JEDC), and Review of Economic Dynamics (RED). ${ }^{6}$ This yields a sample of 514 articles for 2016-17. (See Table 5 for a breakdown by journal and year.) Importantly, this sample selection criterion does not rely on the author-designated JEL codes, deferring instead to the journal editors' judgment regarding what research comes under the macro rubric. The approach also allows us to include articles without JEL codes, which are missing for many journals. This criterion may be overly broad, however, to the extent that the five field journals also publish articles in non-macro areas, such as finance or growth.

Our alternative criterion is to include only those articles with the E ("Macroeconomics and Monetary Economics") JEL code. ${ }^{7}$ This yields a smaller and less heterogenous set of papers from the field journals, ${ }^{8}$ but it allows us to include an additional 94 E-coded articles from 2016-17 from three leading general interest journals: American Economic Review (AER), Quarterly Journal of Economics (QJE), and Review of Economic Studies (ReStud). For 2016-17, a total of 360 articles satisfy this criterion.

Our longitudinal analysis uses articles from macro field journals spanning the 38 years from 1980 through 2017. We limit our sample to the $J M E$ and $J M C B$, arguably the bestknown of the five journals. Both have been published continuously since 1980, whereas the $R E D$ and $A E J$ were launched more recently; therefore, focusing exclusively on the $J M E$ and $J M C B$ will eliminate discontinuities and composition effects from the introduction of new journals. We inventoried papers from six years prior to 2016: 1980, 1990, 2000, 2006,

\footnotetext{
${ }^{6}$ We limit our attention to original research articles. Consequently, we exclude editor's notes and introductions, along with other notes, comments, replies, rejoinders, corrections, extensions, book reviews, discussions, and letters. We also exclude special issues, which are often more narrowly focused on specific topics or methods, and hence may not be representative of publishing trends generally.

${ }^{7}$ Reis (2018) also uses this criterion to select macro articles. Similarly, Kelly and Bruestle (2011) and Card and DellaVigna (2014) rely on JEL codes to classify articles by field.

${ }^{8}$ Excluded are 248 articles that either specify only codes other than E, or give no JEL codes.
} 
2008, and 2010. The total number of articles in this longitudinal subset of the data is 834 (including those from 2016 and 2017). Table 5 gives a breakdown by year and journal.

\section{Findings}

We begin with a look at the distribution of epistemological approaches currently in use, and how it has evolved over time. The most salient finding is the strong emphasis on theory in recent research. As reported in the leftmost column of Table 6, overall $46 \%$ of the 514 papers published in macro field journals in 2016-17 perform quantitative model fitting exercises, and $21 \%$ do pure theory. Together, these two approaches comprise two-thirds of all articles inventoried. Only 25\% published articles perform what could be loosely described as falsification exercises, and the remaining $8 \%$ are descriptive analyses.

Epistemological approach varies significantly across journals, as shown in the next five columns. The $J M C B$ and $A E J$ tend to favor falsification (and to some extent descriptive) papers, while the $J M E, R E D$, and $J E D C$ emphasize theory. The $R E D$ is the most theoretically oriented, with $91 \%$ of articles falling into the theory or model fitting categories. These categories account for $75 \%$ of articles in the $J M E$, and $72 \%$ in the $J E D C$. At the other end of the spectrum is the $J M C B$, with only $39 \%$ of articles in the theory or model fitting category, compared with $56 \%$ classified as falsification.

Macro (JEL code E) articles published in the top three general-interest journals also tend to be theoretically oriented, albeit less so than the field journals. As shown in the last column of 6 , model fitting is less prevalent while pure theory is more common. Together, these categories comprise $57 \%$ of published papers in general interest journals, compared with $68 \%$ in the field journals. Falsification is more common in general interest journals, with $35 \%$ taking that epistemological approach, compared with $25 \%$ in the field journals.

Macroeconomics has not always been so theory-oriented. Figure 1 plots the shares in each of the four categories for the $J M E$ and the $J M C B$ from 1980 to 2017. The figure shows that in 1980, descriptive and falsification approaches (blue shaded areas) were most prevalent, together comprising more than $60 \%$ of the articles in the two journals. This type of research has become less common, however, and accounts for roughly half of papers published in the two journals in 2016-17. The decreasing emphasis on falsification coincides with the growing use of the model-fitting approach (the sienna shaded area). The decrease in pure theory publications, represented by the olive shaded area, coincides with but is smaller than the rise of model fitting. 
Turning to the attributes of the theory used in current research, the first three rows of Table 7 give the breakdown of articles according to equilibrium concept. Dynamic general equilibrium models (the vast majority of which are DSGEs) are most prevalent. As shown in the first row, $41 \%$ of all theory-oriented papers published in macro field journals use DSGEs. More than half do not use DSGEs, however: $24 \%$ build static general equilibrium models, and $35 \%$ employ partial equilibrium analysis.

There is some variation across journals in terms of type of macro model, but it is less pronounced than the differences in epistemological approach. DSGEs account for anywhere from $36 \%(J E D C)$ to $49 \%(J M E)$ of the theoretical papers. A larger-than-average share of the articles published in the $J M C B$ and $J E D C$ are partial equilibrium, Static general equilibrium papers are relatively more common in the $A E J$, and less well represented in the $J M C B$.

The last two columns of Table 7 show that articles using DSGEs are more common in general interest journals (56\%) and the E-designated subset of the macro field journals (58\%), compared to the proportion in the universe of macro field journals (41\%). This reflects the presence in macro journals of papers on non-macro topics (documented below in our tabulation of JEL codes), which are less likely to use DSGE methods.

The share of theory-based articles employing partial equilibrium analysis has been falling steadily since 1980, displaced by static GE and later by DSGE methods. As shown in Figure 2, nearly $80 \%$ of published theory articles in the $J M E$ and $J M C B$ used PE models, with the remaining 20\% using static GEs. By 1990, half were PE while the other half used static GE models. DSGE analysis went from being practically nonexistent in 1990 to accounting for over half of theory articles by 2017. The increasing popularity of DSGE models has come at the expense of both PE and static GE models, whose shares of theory papers have fallen to roughly $30 \%$ and $20 \%$ respectively.

The next three rows of Table 7 focus on how data inform the choice of parameters in theory-oriented research. As of 2016-17, 59\% used calibration (representing $82 \%$ of all quantitative models), while $13 \%$ used statistical methods to fit the model to the data. The remaining $29 \%$ were pure theory, with no use of data. Figure 3 shows that quantitative models generally have been steadily displacing pure theory since the 1980s, with increasing use being made of fit-optimizing methods.

Addressing the critique that macroeconomics gives short shrift to the financial sector, the penultimate row of Table 7 reports the share of pure theory and model-fitting papers that incorporate financial frictions in some form. The critique clearly does not apply to recent 
research: as reported in the table, 30\% of papers published in field journals in 2016-17 included financial frictions. Models with financial frictions are even more common in general interest journals, comprising $41 \%$ in the most recent two years.

There is some validity to the critique that macroeconomics ignored the financial sector prior to the global financial crisis. Figure 4 shows that financial frictions figured prominently in research three decades ago, with $40 \%$ of published theory papers in the $J M E$ and $J M C B$ incorporating this feature in 1980. The share fell over time, perhaps as a result of the growing interest in RBC-style models, reaching a nadir of approximately $10 \%$ in 2000 . There has been a surge in research on these topics after the global financial crisis, not surprisingly. Interestingly, the resurgence in interest seems to have begun several years prior to the crisis.

Focusing on the attributes of models in the DSGE category, Table 8 reports the shares of articles distinguished by genre. New Keynesian (NK) DSGE models are the most common theoretical framework, used in $46 \%$ of the articles published in 2016-17. Although their heyday has passed, RBC models still account for $20 \%$ of published papers. The shares associated with the other genres are all in the single digits.

Next, we turn to a characterization of the empirical methods used in the papers emphasizing conventional econometric analysis.

A striking finding is the degree to which techniques borrowed from research in applied microeconomics (i.e. cross-section and panel methods) have displaced time series analysis. The top two rows of Table 9 show that 55\% of empirical papers published in 2016-17 used applied micro techniques, compared with $45 \%$ for time series methods. Four of the five field journals have applied micro shares greater than or equal to $60 \%$. This style of empirical work is more prevalent in E-designated articles in general interest journals, with $67 \%$ using applied micro methods. (The share exceeds $70 \%$ in the AER and QJE.)

The widespread use of applied micro techniques is a relatively recent phenomenon. Figure 5 shows that time series analysis dominated the macro landscape for nearly two decades, accounting for nearly $80 \%$ of papers published in the $J M E$ and $J M C B$ as recently as 2000 . But the use of applied micro techniques has risen steadily since then, overtaking time series methods in popularity after 2010 .

Closely paralleling the adoption of applied micro methods is the increasing use of microlevel data. As shown in the third and fourth rows of Table 9, nearly half of all articles published in 2016-17 use data at the level of individual firms, households, consumers, or assets. Shares vary across journals, but all exceed 40\%. The top panel of Figure 6 shows that the trend towards microdata-based research dates from 2000, when the share began to 
rise sharply.

A great deal of the data used in recent empirical work comes from proprietary sources. Of the articles in macro field journals published in 2016-2017, 44\% use data that are not publicly available. The share is $50 \%$ or more at the $A E J$ and in macro articles in general interest journals. The bottom panel of Figure 6 illustrates the rapid rise in the use of proprietary data, from just over $10 \%$ in 1980 to nearly half in recent years.

Table 9 shows that $64 \%$ of applied micro papers use reduced-form analysis while structural and experimentalist techniques each account for $14 \%$.

Finally, we turn to the question of whether macroeconomics is as insular in its choice of topics as is sometimes perceived. (We have already seen that it has freely borrowed the methods commonly used in other fields.) To get a sense of the extent of interaction between macroeconomics and other fields within economics, we tabulate the JEL codes for each article in our 2016-17 inventory, excluding JME, for which only four articles reported codes in $2016 .^{9}$

Panel A of Table 10 shows that the research published in macroeconomics journals spans a wide range of other fields. Prominent subfields are Financial Economics, appearing in $36 \%$ of papers, and Microeconomics, appearing in $29 \%$ of papers. Remarkably, only $63 \%$ of papers published in macroeconomics journals list JEL Code E, implying a 37\% share on non-macro topics. Only $8 \%$ of published papers list JEL code F (International Economics), indicative of a strong emphasis on closed-economy analysis.

The range of JEL codes represented in macroeconomics journals is not merely the result of the five macro field journals publishing non-macro papers (although that is true in many cases). In Panel B of Table 10, we restrict attention to the subset of E-designated articles to see whether these also incorporate other subfields. The first row shows that $76 \%$ of these papers report a topic outside of macro and monetary economics. Of these, Financial economics $(\mathrm{G})$ and Microeconomics (D) are the most common areas of cross-fertilization. The majority of Financial papers appear in the AEJ (29\%) and $J M C B$ (29\%), while micro papers most frequently appear in the AEJ (39\%) and JEDC (27\%).

\section{Conclusion}

In this paper, we have analyzed over 1,200 peer-reviewed publications in leading journals, enabling us to document evidence about macroeconomic research today and over the past

\footnotetext{
${ }^{9}$ Even for the other four journals, JEL codes are not consistently reported.
} 
38 years. Our focus has been on four aspects of the research: underlying epistemological approaches, characteristics of the theoretical frameworks, empirical methods, and research topics. Overall, we concur with Reis's (2018) view that macroeconomics is a rich and evolving field, encompassing a wide variety of theories, methods and topics. Contrary to some economists' perception, there is more to macroeconomics than New Keynesian DSGEs.

One theme to emerge from our survey is the degree to which macroeconomics has become a theory-driven field. Macro models, virtually all of which incorporate microfoundations, feature prominently in two-thirds of all articles published in 2016-17. The majority of these are quantitative models, with parameters chosen to fit one or more moments of the data, and intended to provide quantitative predictions or perform welfare analysis. Papers lacking a substantial theory section are rare. Interestingly, this runs counter to the trend in applied microeconomics, where recent research has tended to deemphasize formal theoretical modeling (Biddle and Hamermesh, 2017).

A second theme is that research based on fitting models to "explain" observed patterns in the data has, to a large extent, displaced falsification and descriptive analyses. These approaches, which once dominated macroeconomics, now account for only one-fourth of the articles published in macro journals in the past two years. Interestingly, this is less true of E-designated articles in general interest journals, however, which had a relatively greater emphasis on falsification.

The de-emphasis of falsification runs counter to the distinctly Popperian "Keynesian counterrevolution" philosophy articulated by Lucas and Sargent (1979):

"This research line being pursued by a number of us involves the attempt to discover a particular, econometrically testable equilibrium theory of the business cycle, one that can serve as the foundation for quantitative analysis of macroeconomic policy." (Italics added.)

Instead, the dominant epistemological approach is now that expressed by Sims (1996):

"It was once common for economists to think of the scientific enterprise as formulating testable hypotheses and confronting them with data. True hypotheses would survive the tests, while false ones would be eliminated. The science-asdata-compression view lets us see the limits of this hypothesis testing view. The latter is dependent on the idea that there are true and false theories, when in fact the degree to which theories succeed in reducing data can be a continuum. The theory that planetary orbits are ellipses is only approximate if measurements are 
made carefully enough. It does not seem helpful to say therefore it is false and should be rejected."

The absence of clear criteria for rejecting theories in this approach to macroeconomic research has led some (e.g. Summers, 1991; Korinek, 2017) to express doubts about the field's status as a bona fide science.

One plausible explanation for the trend towards the model-fitting approach is the inherent difficulty of econometrically identifying macroeconomic models, given the joint endogeneity of virtually all macroeconomic variables. (How does one estimate the response of inflation to the unemployment rate when unemployment may be affected by inflation?) Finding the defensible overidentifying restrictions necessary to test a model is even harder. Using microfoundations to impose structure on the model solves the identification problem; although as Romer (2016) points out, identification assumptions of this type tend to be opaque and empirically unsubstantiated. ${ }^{10}$

New technology is also likely to have contributed to the development of quantitative macro models, and the model-fitting epistemology associated with them (e.g. Sergi, 2017). Increased computing power and the development of easy-to-use software (e.g. Dynare) has made it possible to solve and fit ever larger and more complex models, such as that of Smets and Wouters (2007), which are better able to mimic the economy than the small "toy" models used previously.

The difficulty of identifying macroeconomic relationships from aggregate data may also help explain the growing use of applied microeconomic methods and microdata. Significantly, Nakamura and Steinsson (2018) focus almost exclusively on micro-based identification strategies, rather than the methods associated with equilibrium business cycle analysis and structural VARs. Prominent examples (not in our dataset) include Mian and Sufi (2009, 2012, 2014), which use microdata to explore a wide range of macro questions, including the impact of subprime lending, house price declines, and fiscal policy. However, the increasing use of proprietary microdata does raise concerns about the ability of other researchers to replicate and independently corroborate published results.

A third theme emerging from our findings is that although DSGEs have become the "go-to" modeling framework in macroeconomics, they have not entirely taken over the field; partial equilibrium models and conventional econometric methods continue to be used. This reflects Blanchard's (2009) view that

"Partial equilibrium modeling and estimation are essential to understanding

\footnotetext{
${ }^{10}$ Romer sarcastically refers to these assumptions as "facts with unknown truth values."
} 
the particular mechanisms of relevance to macroeconomics. Only when they are well understood does it become essential to understand their general equilibrium effects. Not every macroeconomist should be working on general equilibrium models (there is such a thing as division of labour)."

Fourth, our survey of macroeconomic research suggests that it is not fair to indict macroeconomics for ignoring financial frictions and the financial sector more broadly. ${ }^{11}$ That may have been true 20 years ago, but nearly one-third of pure-theory or quantitative-modeling articles published in field journals in the past two years include these features, $40 \%$ in general interest journals. There is more work to be done, of course; but if macroeconomists fail to anticipate the next crisis, it will not be for lack of trying. ${ }^{12}$

In the end, we hope our findings will inform discussions about the current state of macroeconomics, its past evolution, and the directions it is likely to take in the future. A number of questions merit further investigation. An examination of identification issues may be useful, for example; and a closer look at how financial intermediaries are modeled could tell us more about the inclusion of financial factors in macroeconomic analysis. Comparisons between research in field journals, general-interest journals and policy institutions (e.g. central banks) might also be informative. And, an analysis of citation patterns might provide some insights as to which types of research were most influential in terms determining the direction of future research.

\footnotetext{
${ }^{11}$ This critique has been expressed by De Grawe (2009), Skidelsky (2009) and Stiglitz (2018), among many others.

${ }^{12}$ See McKibbin and Stoeckel (2018) and Vines and Wills (2018) for discussions of fruitful directions for research on this topic.
} 
Table 1: Summary of Classification Scheme

For all papers

Epistemology

description, falsification, model fitting, pure theory

For quantitative modeling and pure theory papers

Equilibrium concept partial equilibrium, general equilibrium, DSGE

Financial sector does it include intermediation or financial frictions?

\section{For quantitative modeling papers}

Model fitting method calibration, optimization

\section{For DSGEs}

Genre

RBC, NK, monetary, trade, search/matching, asset pricing, OLG/life-cycle

\section{For papers using econometric methods}

Method, general

Model, specific

Data structure

Unit of observation

Microdata

Data source time series, applied micro

reduced-form, structural, experimentalist, descriptive time series, cross section, panel

country, state, MSA, industry, asset, product, firm, subsidiary household, individual

is the unit of observation individual firms, plants, households, etc.?

public, proprietary, lab/field experiment, survey

For papers using time series or panel data

Frequency annual, quarterly, monthly, weekly, daily, intra-day 
Table 2: Examples of Epistemological Approaches

\begin{tabular}{|c|c|c|}
\hline Wulfsberg (2016) & Description & $\begin{array}{l}\text { Uses micro data to document the relationship be- } \\
\text { tween the size and frequency of price changes dur- } \\
\text { ing high- and low-inflation periods. }\end{array}$ \\
\hline Bems and Johnson (2017) & Description & $\begin{array}{l}\text { Constructs new indexes of real effective exchange } \\
\text { rates. }\end{array}$ \\
\hline Fuhrer and Tootell (2008) & Falsification & $\begin{array}{l}\text { Econometrically tests the hypothesis that the Fed } \\
\text { responds to stock market fluctuations. Time se- } \\
\text { ries econometric model. }\end{array}$ \\
\hline Khan and Reza (2017) & Falsification & $\begin{array}{l}\text { Shows that standard DSGE models with housing } \\
\text { are qualitatively inconsistent with the data. Cal- } \\
\text { ibrated New Keynesian DSGE. }\end{array}$ \\
\hline Ravenna and Walsh (2006) & Model fitting & $\begin{array}{l}\text { Evaluates optimal monetary policy rule in the } \\
\text { presence of the cost channel. Calibrated New } \\
\text { Keynesian DSGE. }\end{array}$ \\
\hline Gertler et al. (2008) & Model fitting & $\begin{array}{l}\text { Shows that including wage rigidity helps a } \\
\text { medium-scale macro model fit the data. Opti- } \\
\text { mized New Keynesian DSGE. }\end{array}$ \\
\hline Woodford (2008) & Pure theory & $\begin{array}{l}\text { Uses a theoretical model to evaluate the argument } \\
\text { that monetary aggregates should play a role in } \\
\text { monetary policy. New Keynesian DSGE. }\end{array}$ \\
\hline Phelan (2016) & Pure theory & $\begin{array}{l}\text { Solves a model numerically to illustrate the re- } \\
\text { lationship between bank equity and several real } \\
\text { macroeconomic variables, but notes that the } \\
\text { model parameters "are not the result of careful } \\
\text { calibration." Asset pricing model. }\end{array}$ \\
\hline
\end{tabular}


Table 3: Examples of Equilibrium Concepts and Other Model Characteristics

Roberts (1980)

Pries (2016)

Gertler and Rogoff (1990)

Karabarbounis (2016)

Cúrdia and Woodford (2016)

Ireland (2000)
Partial Models investors' demand for bonds of different maturities to consider the effects of asset supplies on term premiums. Pure theory epistemology.

Partial Builds a search and matching model of the labor market, shows how uncertainty shocks can give rise to the Beveridge Curve. Model fitting epistemology, calibrated.

General Develops an open-economy model of intertemporal trade under asymmetric information to analyze North-South capital flows. Pure theory epistemology.

General Develops a life-cycle model with an endogenous labor supply elasticity to determine optimal tax policy. Model fitting epistemology, calibrated.

DSGE Extends a standard New Keynesian model to allow for a spread in the interest rate earned by savers and paid by borrowers. Model fitting epistemology, includes a financial sector.

DSGE Characterizes the Fed's response to technology shocks, using a model with money in the utility function. Model fitting epistemology, monetary model. 
Table 4: Examples of Econometric Methods and Data Characteristics

Fama (1990)

Sack (2000)

Rupert et al. (2000)

Brueckner et al. (2016)
Time series

Uses time series data on interest rates and inflation to estimate autoregressive models showing that the term structure has useful information for forecasting future interest rates at longer horizons as well as the business cycle. Monthly data.

Time series Uses a structural VAR to show that uncertainty about the structure of the economy can explain the Fed's gradual adjustment of the interest rate. Monthly data.

Applied micro Estimates households' intertemporal elasticities of substitution. Structural. Householdlevel cross-sectional time use survey data.

Edwards and Magendzo (2006) Applied micro Estimates "treatment effects" of strict dollarization. Experimentalist. Cross-section, country-level data.

Applied micro Use a panel of loan level data to estimate whether the growth rate in housing prices explains changes in the market share of alternative mortgage products. Reduced-form. Quarterly asset-level panel data, proprietary. 
Table 5: Number of Articles by Year and Journal

\begin{tabular}{lccccccc}
\hline & & \multicolumn{5}{c}{ Macro field journal } & \multirow{2}{*}{$\begin{array}{c}\text { General } \\
\text { interest }\end{array}$} \\
\cline { 3 - 6 } & All & $J M E$ & $J M C B$ & AEJ & JEDC & RED & JMC \\
\hline 2017 & 302 & 32 & 51 & 32 & 101 & 34 & 52 \\
2016 & 306 & 55 & 53 & 29 & 90 & 37 & 42 \\
2010 & 116 & 62 & 54 & & & & \\
2008 & 122 & 66 & 56 & & & & \\
2006 & 181 & 95 & 86 & & & & \\
2000 & 80 & 52 & 28 & & & & \\
1990 & 69 & 40 & 29 & & & & \\
1980 & 71 & 34 & 37 & & & & \\
Total & 1,247 & 436 & 394 & 61 & 191 & 71 & 94 \\
\hline
\end{tabular}

Note: The journal abbreviations are as follows: AEJ is American Economic Association: Macroeconomics, JEDC is Journal of Economic Dynamics and Control, JME is Journal of Monetary Economics, JMCB is Journal of Money, Credit and Banking, and RED is Review of Economic Dynamics. The numbers exclude notes, comments, replies, letters, book reviews and articles published in special issues. The general interest journals are the American Economic Review, Quarterly Journal of Economics and Review of Economic Studies, and the numbers indicate the number of articles with JEL code E ("Macroeconomics and Monetary Economics"). See section 3 for details.

Table 6: Epistemological Approaches

\begin{tabular}{|c|c|c|c|c|c|c|c|c|}
\hline & \multicolumn{6}{|c|}{ Macro field journals, all JEL codes } & \multicolumn{2}{|c|}{ E-code articles } \\
\hline & All & $A E J$ & $J E D C$ & $J M E$ & $J M C B$ & $R E D$ & Field & General \\
\hline \multicolumn{9}{|l|}{ Shares, \% } \\
\hline Model fitting & 46 & 49 & 42 & 60 & 22 & 73 & 53 & 33 \\
\hline Pure theory & 21 & 11 & 30 & 15 & 17 & 18 & 15 & 24 \\
\hline Falsification & 25 & 30 & 17 & 18 & 56 & 6 & 25 & 35 \\
\hline Descriptive & 8 & 10 & 11 & 7 & 5 & 3 & 7 & 7 \\
\hline Number of articles & 514 & 61 & 191 & 87 & 104 & 71 & 266 & 94 \\
\hline
\end{tabular}

Note: The shares are calculated relative to the total number of articles 2016 and 2017, reported in the bottom row, classified according to the criteria described in section 2.1. (The shares may not sum to 100 due to rounding.) The journal abbreviations are given in the note to Table 5 . 
Table 7: Theory Attributes

\begin{tabular}{|c|c|c|c|c|c|c|c|c|}
\hline & \multicolumn{6}{|c|}{ Macro field journals, all JEL codes } & \multicolumn{2}{|c|}{ E-code articles } \\
\hline & All & $A E J$ & $J E D C$ & $J M E$ & $J M C B$ & $R E D$ & Field & General \\
\hline \multicolumn{9}{|l|}{ Shares, $\%$} \\
\hline \multicolumn{9}{|l|}{ Scope of equilibrium } \\
\hline Dynamic general & 41 & 41 & 36 & 49 & 48 & 43 & 58 & 56 \\
\hline General & 24 & 43 & 20 & 22 & 13 & 29 & 21 & 20 \\
\hline Partial & 35 & 16 & 44 & 29 & 40 & 29 & 21 & 24 \\
\hline \multicolumn{9}{|l|}{ Model fit } \\
\hline Calibrated & 59 & 70 & 49 & 66 & 53 & 71 & 67 & 41 \\
\hline Optimized & 13 & 11 & 14 & 15 & 8 & 13 & 16 & 19 \\
\hline None & 29 & 19 & 36 & 18 & 43 & 19 & 19 & 41 \\
\hline Financial frictions & 30 & 41 & 21 & 32 & 55 & 27 & 33 & 41 \\
\hline Number of articles & 343 & 37 & 138 & 65 & 40 & 63 & 178 & 54 \\
\hline
\end{tabular}

Note: The shares are calculated relative to the number of theory-oriented articles from 2016 and 2017, reported in the bottom row, classified according to the criteria described in section 2.2. (The shares may not sum to 100 due to rounding.) The journal abbreviations are given in the note to Table 5 .

Table 8: DSGE Genres

\begin{tabular}{lcccccc}
\hline & \multicolumn{5}{c}{ Field journals } \\
\cline { 2 - 7 } & All & AEJ & JEDC & JME & $J M C B$ & RED \\
\hline Shares, \% & & & & & & \\
New Keynesian & 46 & 40 & 50 & 45 & 68 & 26 \\
Real business cycle & 20 & 33 & 22 & 10 & 18 & 22 \\
Asset pricing & 3 & 7 & 2 & 10 & 0 & 0 \\
Growth & 5 & 7 & 4 & 3 & 0 & 11 \\
Monetary & 4 & 7 & 4 & 3 & 5 & 4 \\
OLG/life cycle & 6 & 7 & 6 & 10 & 0 & 4 \\
Search/matching & 6 & 0 & 0 & 10 & 0 & 19 \\
Trade & 1 & 0 & 2 & 3 & 0 & 0 \\
Other & 8 & 0 & 10 & 3 & 9 & 15 \\
Number of articles & 143 & 15 & 50 & 29 & 22 & 27 \\
\hline
\end{tabular}

Note: The shares are calculated relative to the number of theory-oriented articles from 2016 and 2017, reported in the bottom row, classified according to the criteria described in section 2.2. (The shares may not sum to 100 due to rounding.) The journal abbreviations are given in the note to Table 5 . 
Table 9: Empirical Methods

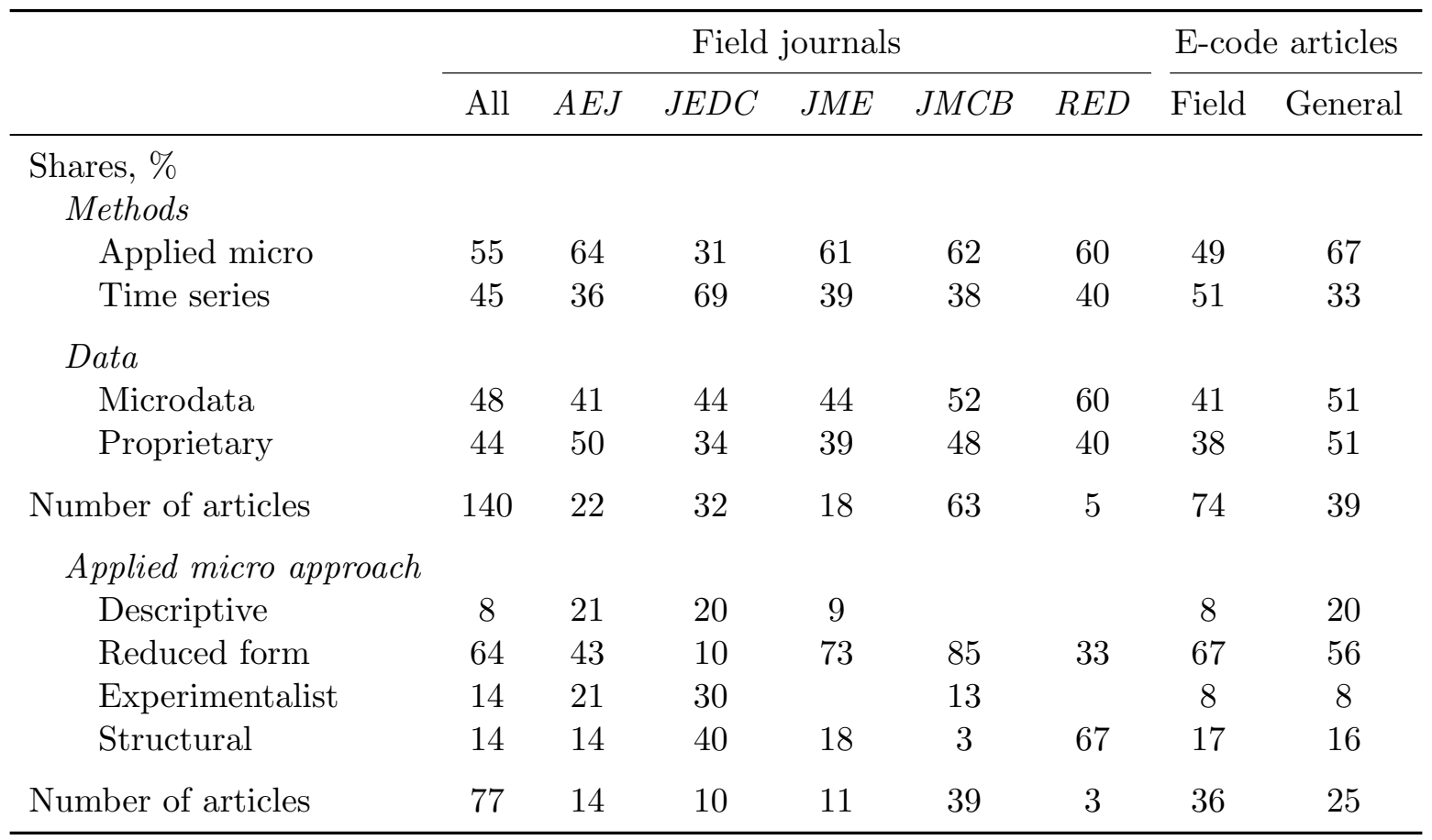

Note: The methods and data shares are calculated relative to the number of articles in the descriptive and falsification categories from 2016 and 2017, reported in row 5, classified according to the criteria described in section 2.3. (The shares may not sum to 100 due to rounding.) The applied micro approach shares are calculated relative to the number of applied micro articles from 2016 and 2017, reported in the bottom row. The journal abbreviations are given in the note to Table 5 . 
Table 10: Research Topics

Panel A: Distribution of Topics

\begin{tabular}{lccccc}
\hline & All & AEJ & JEDC & JMCB & RED \\
\hline Shares, \% & & & & & \\
Macro and Monetary (E) & 63 & 68 & 57 & 65 & 74 \\
Financial (G) & 36 & 27 & 37 & 51 & 20 \\
Microeconomics (D) & 29 & 40 & 31 & 22 & 26 \\
Mathematical Methods (C) & 26 & 8 & 42 & 16 & 12 \\
Development (O) & 10 & 28 & 7 & 1 & 17 \\
Public Economics (H) & 9 & 15 & 7 & 2 & 21 \\
Labor Economics (J) & 11 & 23 & 4 & 3 & 29 \\
Industrial Organization (L) & 8 & 22 & 7 & 4 & 6 \\
International Economics (F) & 8 & 15 & 7 & 8 & 8 \\
All other JEL codes & 28 & 35 & 27 & 18 & 39 \\
Articles with JEL codes & 401 & 60 & 184 & 91 & 66 \\
Average \# codes per article & 2.2 & 2.8 & 2.1 & 1.8 & 2.2 \\
\hline
\end{tabular}

Panel B: Macro and Monetary Papers with Other Topics

\begin{tabular}{lccccc}
\hline & All & AEJ & JEDC & JMCB & RED \\
\hline Shares, \% & & & & & \\
Any JEL code other than E & 76 & 88 & 78 & 59 & 84 \\
Financial (G) & 24 & 29 & 20 & 29 & 20 \\
Microeconomics (D) & 26 & 39 & 27 & 19 & 24 \\
Mathematical Methods (C) & 22 & 10 & 34 & 19 & 12 \\
Labor Economics (J) & 10 & 5 & 6 & 3 & 31 \\
Development Economics (O) & 9 & 29 & 5 & 0 & 10 \\
International Economics (F) & 9 & 22 & 10 & 2 & 4 \\
\hline
\end{tabular}

Note: The shares are calculated relative to the number of articles with JEL codes published in 2016 and 2017, reported on the penultimate row of panel A. 
Figure 1: Evolution of Epistemological Approaches

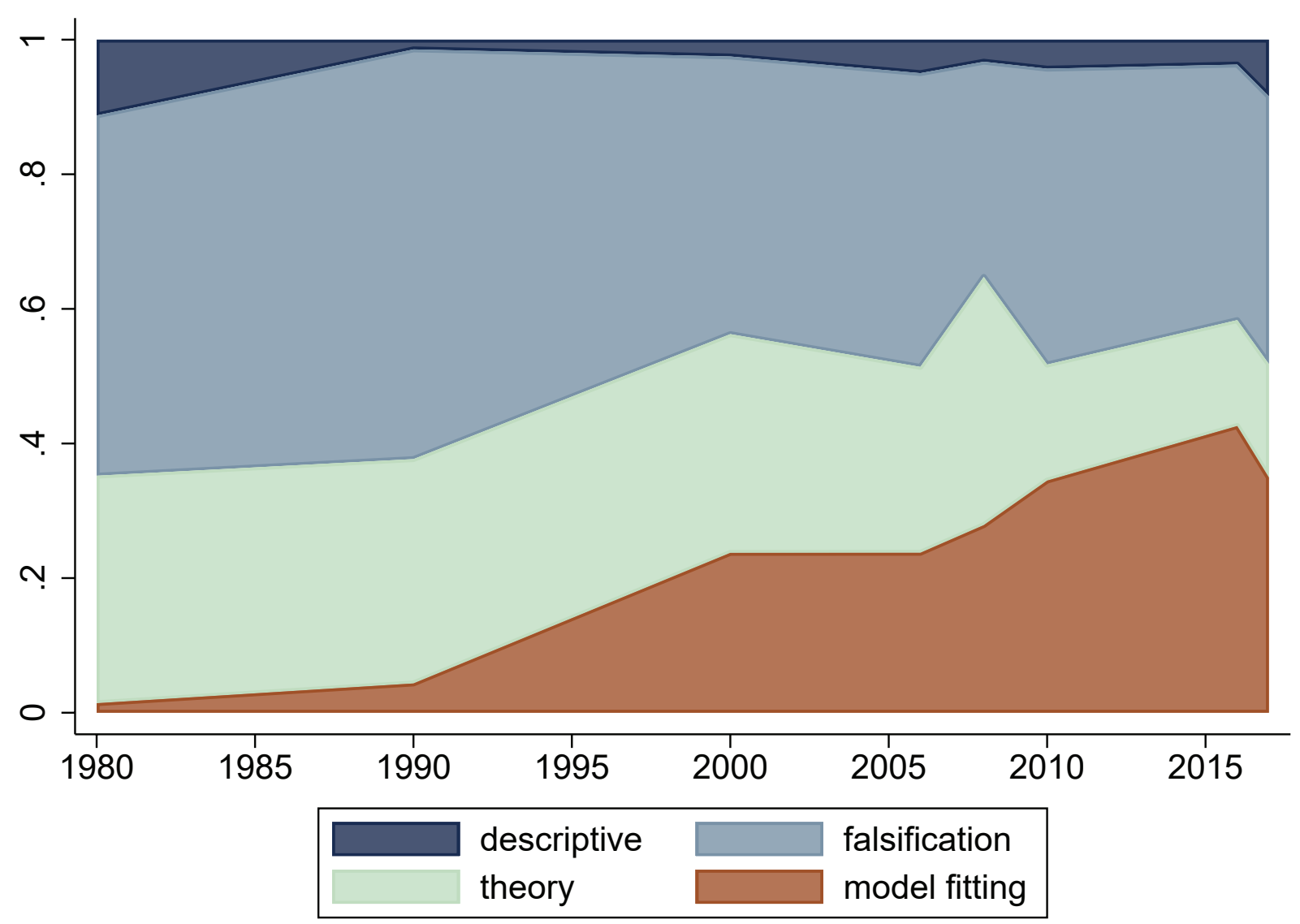

Note: This figure reports the share of published macroeconomics papers focusing on each of the four epistemological approaches (descriptive, falsification, model fitting, and pure theory) among articles in our sample, described in Section 3, published in the JME and the JMCB for the years 1980, 1990, 2000, 2006, 2008, 2010, 2016 and 2017. 
Figure 2: Scope of Equilibrium Over Time

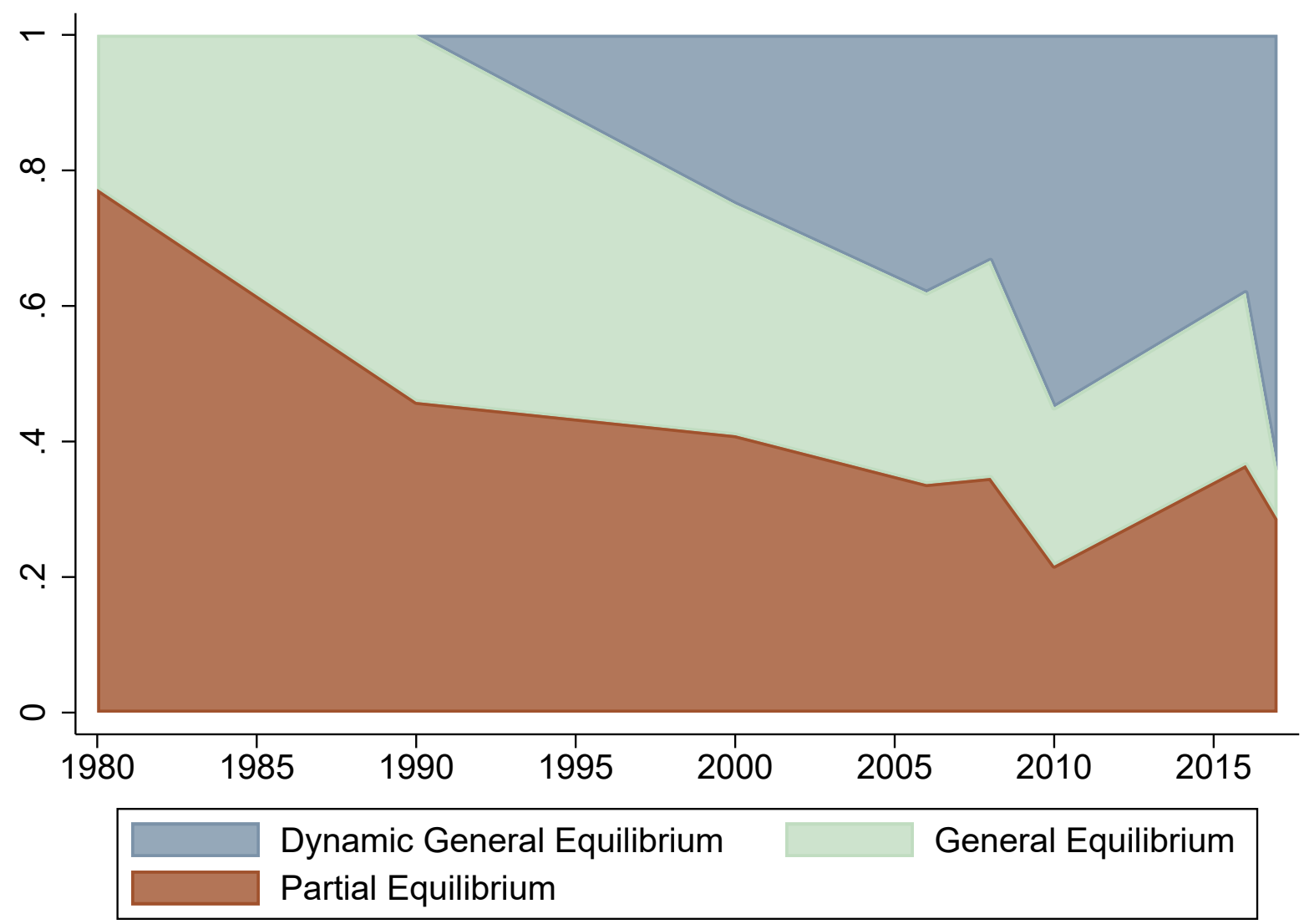

This figure reports the share of published macroeconomics papers analyzing each of the three equilibrium concepts (partial equilibrium, general equilibrium, dynamic stochastic general equilibrium) among articles in our sample, described in Section 3, published in the JME and the JMCB for the years 1980, 1990, 2000, 2006, 2008, 2010, 2016 and 2017. 
Figure 3: Model Fitting Methods Over Time

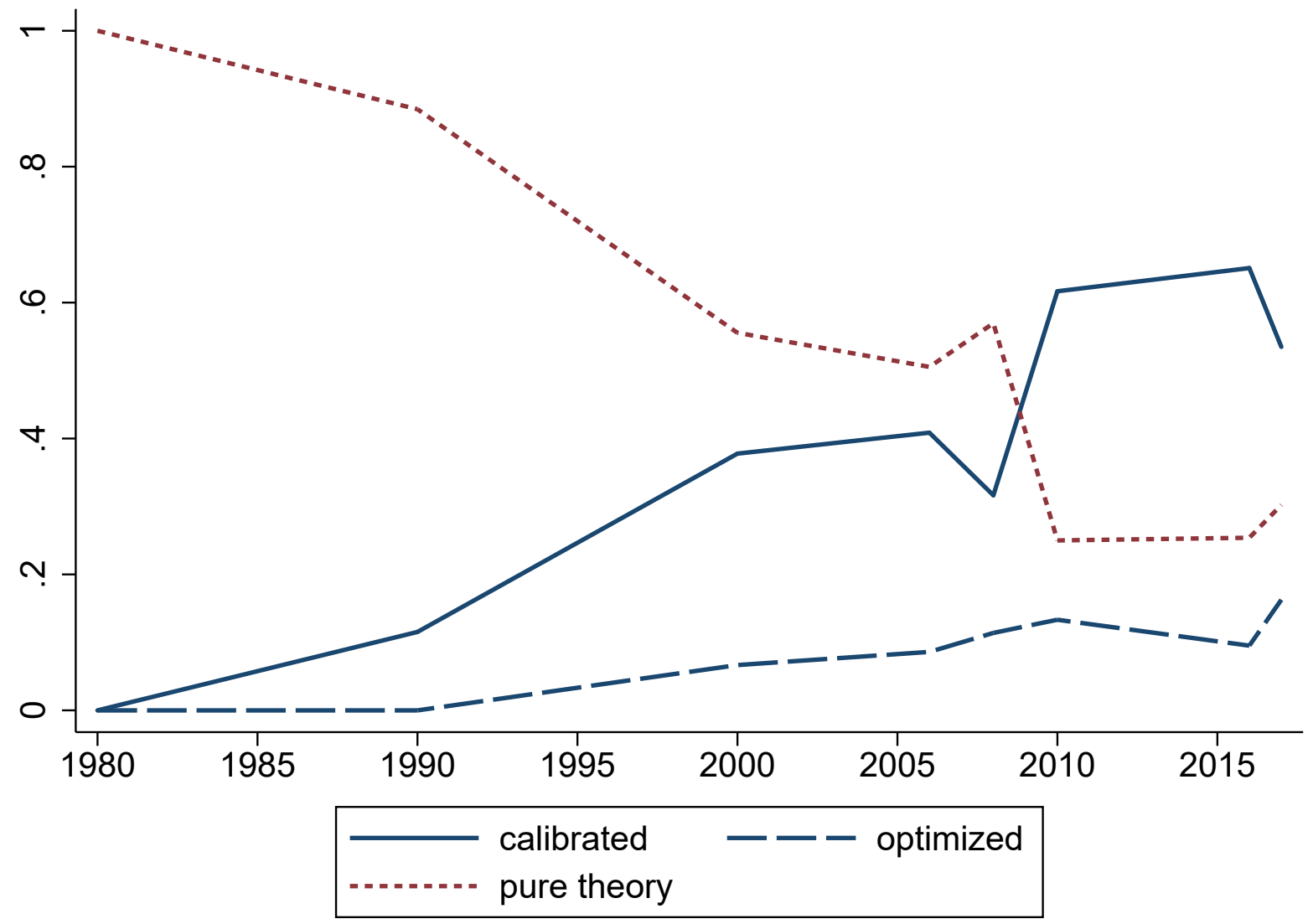

Note: This figure reports the share of published macroeconomics papers emphasizing theory that discipline model parameters using calibration methods, optimization methods, or neither (defined in Section 2) among articles in our sample, described in Section 3, published in the JME and the JMCB for the years 1980, 1990, 2000, 2006, 2008, 2010, 2016 and 2017. 
Figure 4: Financial Intermediation Over Time

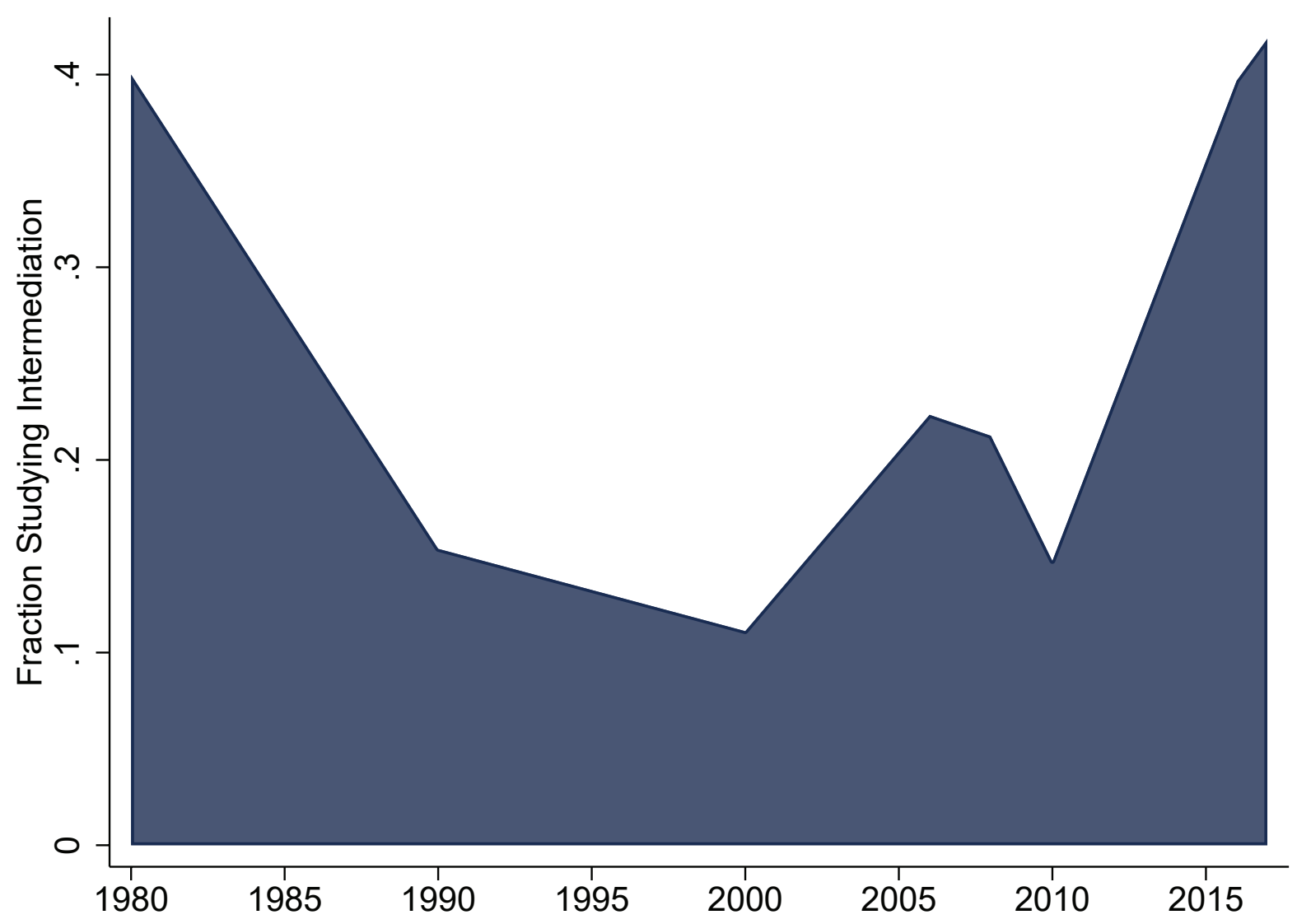

Note: This figure reports the share of published macroeconomics papers emphasizing theory that analyze financial intermediation (defined in Section 2) among articles in our sample, described in Section 3, and published in the JME and the JMCB for the years 1980, 1990, 2000, 2006, 2008, 2010, 2016 and 2017. 
Figure 5: Time Series vs Applied Micro Techniques Over Time

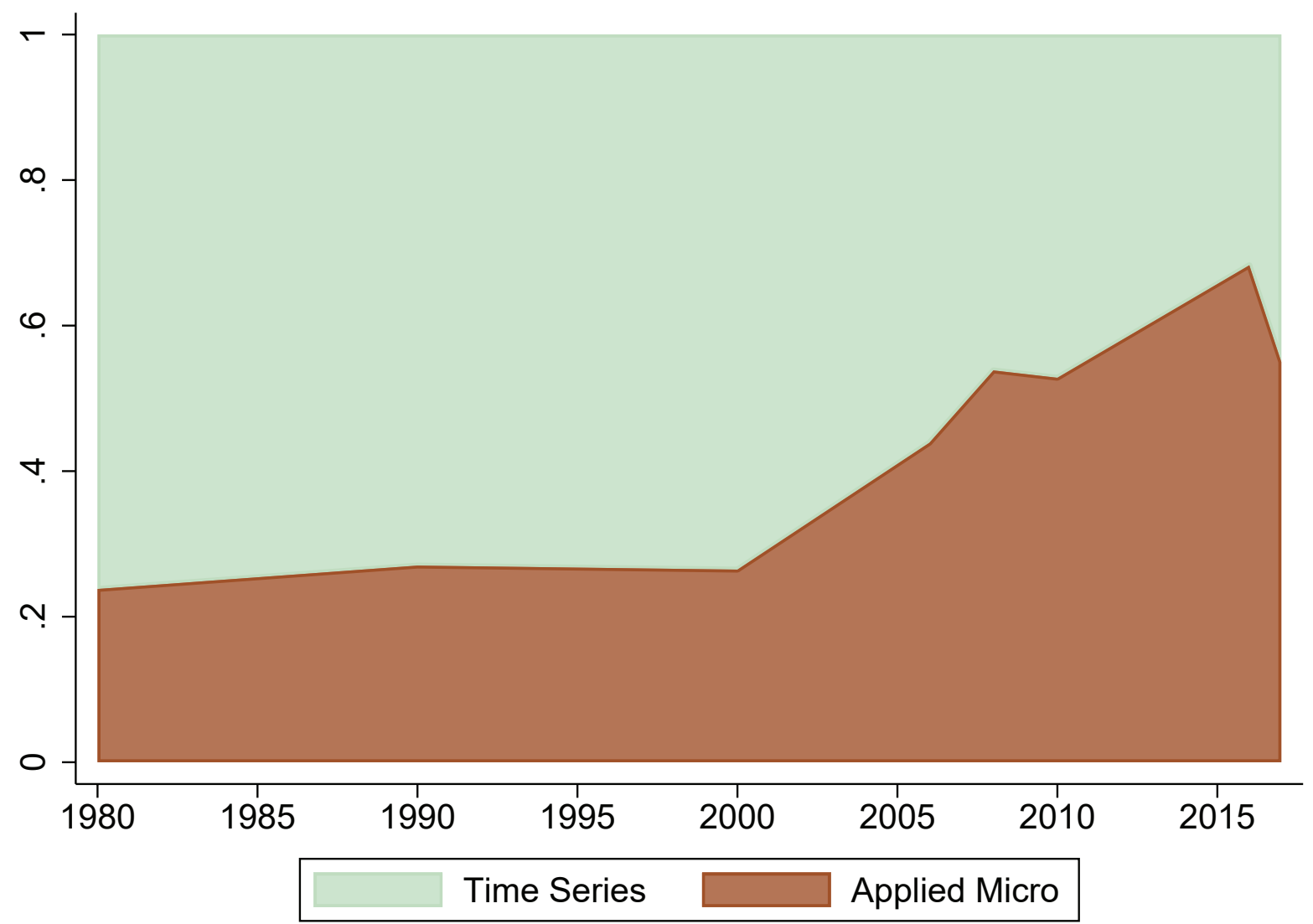

Note: This figure reports the share of published empirical articles primarily using either time series and applied micro econometrics techniques among articles in our sample, described in Section 3, and published in the JME and the JMCB for the years 1980, 1990, 2000, 2006, 2008, 2010, 2016 and 2017. 
Figure 6: Empirical Papers Using Microdata and Proprietary Data
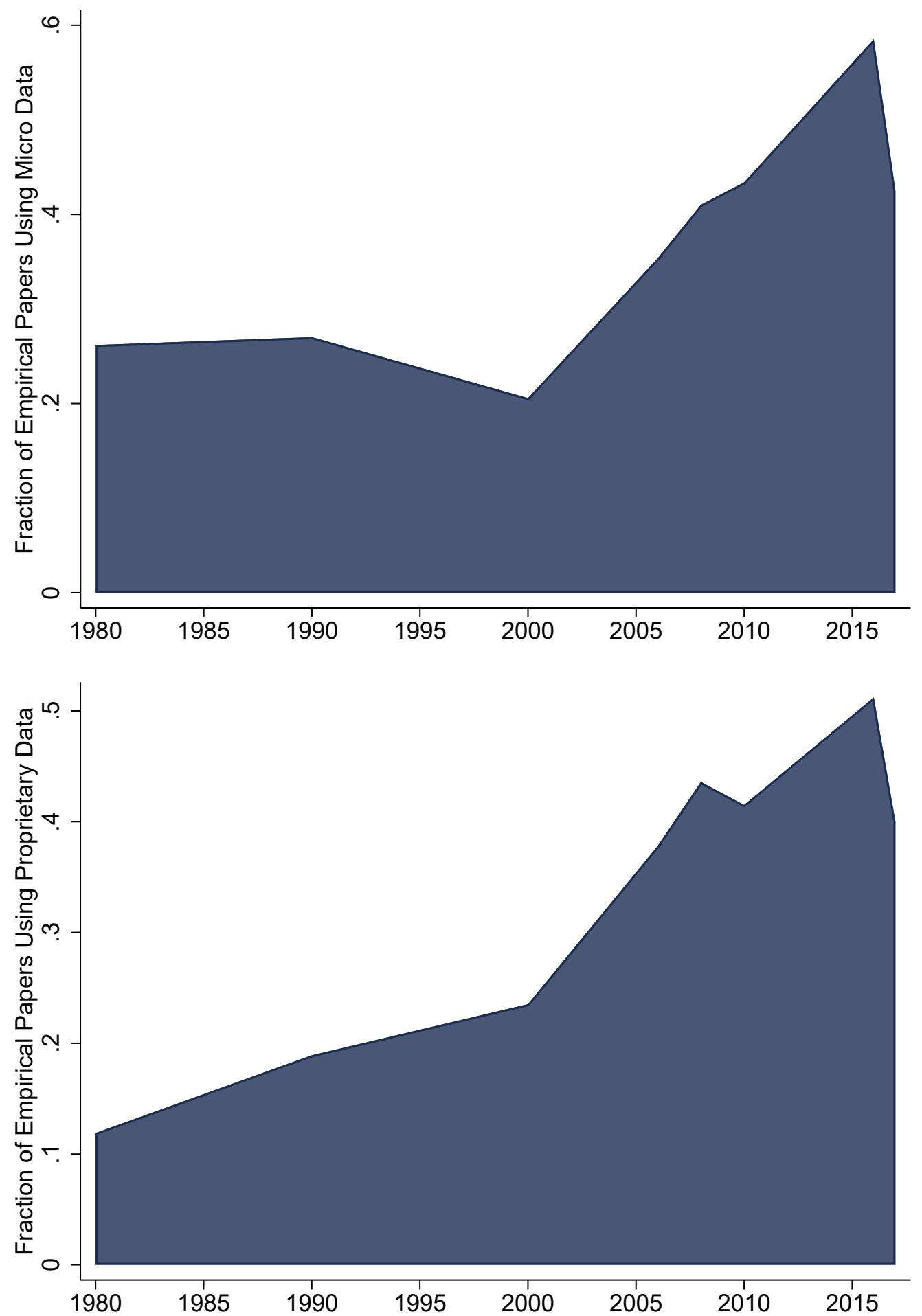

Note: This figure reports the share of published empirical articles using microdata (top panel, defined in Section 2) and proprietary data (bottom panel) among articles in our sample, described in Section 3, and published in the JME and the JMCB for the years 1980, 1990, 2000, 2006, 2008, 2010, 2016 and 2017. 


\section{References}

Adelman, I. and Adelman, F. L. (1959). The dynamic properties of the Klein-Goldberger model. Econometrica, 27(4):596-625.

Bems, R. and Johnson, R. C. (2017). Demand for value added and value-added exchange rates. American Economic Journal: Macroeconomics, 9(4):45-90.

Biddle, J. E. and Hamermesh, D. S. (2017). Theory and Measurement: Emergence, Consolidation, and Erosion of a Consensus. History of Political Economy, 49(Supplement):34-57.

Blanchard, O. (2009). The state of macro. Annual Review of Economics, 1(1):209-228.

Brueckner, J. K., Calem, P. S., and Nakamura, L. I. (2016). House price expectations, alternative mortgage products, and default. Journal of Money, Credit and Banking, 48(1):81112.

Card, D. and DellaVigna, S. (2014). Page limits on economics articles: Evidence from two journals. Journal of Economic Perspectives, 28(3):149-68.

Cúrdia, V. and Woodford, M. (2016). Credit frictions and optimal monetary policy. Journal of Monetary Economics, 84:30-65.

De Grawe, P. (2009). Warring economists are carried along by the crowd. Financial Times.

Edwards, S. and Magendzo, I. I. (2006). Strict dollarization and economic performance: An empirical investigation. Journal of Money, Credit and Banking, 38(1):269-282.

Fama, E. F. (1990). Term-structure forecasts of interest rates, inflation and real returns. Journal of Monetary Economics, 25(1):59-76.

Friedman, M. (1946). Lange on price flexibility and employment: A metgodological criticism. The American Economic Review, 36(4):613-631.

Fuhrer, J. and Tootell, G. (2008). Eyes on the prize: How did the Fed respond to the stock market? Journal of Monetary Economics, 55(4):796-805.

Gertler, M. and Rogoff, K. (1990). North-south lending and endogenous domestic capital market inefficiencies. Journal of Monetary Economics, 26(2):245-266.

Gertler, M., Sala, L., and Trigari, A. (2008). An estimated monetary DSGE model with unemployment and staggered nominal wage bargaining. Journal of Money, Credit and Banking, 40(8):1713-1764.

Ireland, P. N. (2000). Interest rates, inflation, and Federal Reserve policy since 1980. Journal of Money, Credit and Banking, 32(3):417-434.

Karabarbounis, M. (2016). A road map for efficiently taxing heterogeneous agents. American Economic Journal: Macroeconomics, 8(2):182-214. 
Kelly, M. A. and Bruestle, S. (2011). Trend of subjects published in economics journals 1969-2007. Economic Inquiry, 49(3):658-673.

Khan, H. and Reza, A. (2017). House prices and government spending shocks. Journal of Money, Credit and Banking, 49(6):1247-1271.

Korinek, A. (2017). Thoughts on DSGE macroeconomics: Matching the moment but missing the point? In Guzman, M., editor, Economic Theory and Public Policies: Joseph Stiglitz and the Teaching of Economics. Columbia University Press.

Kydland, F. E. and Prescott, E. C. (1996). The computational experiment: An econometric tool. Journal of Economic Perspectives, 10(1):69-85.

Lucas, R. and Sargent, T. J. (1979). After Keynesian macroeconomics. Federal Reserve Bank of Minneapolis Quarterly Review, 3(2):1-16.

McKibbin, W. J. and Stoeckel, A. (2018). Modelling a complex world: Improving macromodels. Oxford Review of Economic Policy, 34(1-2):329-347.

Mian, A. and Sufi, A. (2009). The consequences of mortgage credit expansion: Evidence from the U.S. mortgage default crisis. The Quarterly Journal of Economics, 124(4):1449-1496.

Mian, A. and Sufi, A. (2012). The effects of fiscal stimulus: Evidence from the 2009 cash for clunkers program. The Quarterly Journal of Economics, 127(3):1107-1142.

Mian, A. and Sufi, A. (2014). What explains the 2007-2009 drop in employment? Econometrica, 82(6):2197-2223.

Nakamura, E. and Steinsson, J. (2018). Identification in macroeconomics. Journal of Economic Perspectives, 32(3):59-86.

Phelan, G. (2016). Financial intermediation, leverage, and macroeconomic instability. American Economic Journal: Macroeconomics, 8(4):199-224.

Pries, M. J. (2016). Uncertainty-driven labor market fluctuations. Journal of Economic Dynamics and Control, 73:181-199.

Ravenna, F. and Walsh, C. E. (2006). Optimal monetary policy with the cost channel. Journal of Monetary Economics, 53(2):199 - 216.

Reis, R. (2018). Is something really wrong with macroeconomics? Oxford Review of Economic Policy, 34(1-2):132-155.

Roberts, G. S. (1980). Term premiums in the term structure of interest rates. Journal of Money, Credit and Banking, 12(2):184-197.

Romer, P. (2016). The trouble with macroeconomics. The American Economist.

Rupert, P., Rogerson, R., and Wright, R. (2000). Homework in labor economics: Household production and intertemporal substitution. Journal of Monetary Economics, 46(3):557579 . 
Sack, B. (2000). Does the Fed act gradually? A VAR analysis. Journal of Monetary Economics, 46(1):229-256.

Sergi, F. (2017). The standard narrative on history of macroeconomics: Central banks and DSGE models. Working paper, Annual Meeting of the History of Economics Society.

Sims, C. A. (1996). Macroeconomics and methodology. Journal of Economic Perspectives, 10(1):105-120.

Skidelsky, R. (2009). How to rebuild a shamed subject. Financial Times.

Smets, F. and Wouters, R. (2007). Shocks and frictions in us business cycles: A Bayesian DSGE approach. The American Economic Review, 97(3):586-606.

Stiglitz, J. E. (2018). Where modern macroeconomics went wrong. Oxford Review of Economic Policy, 34(1-2):70-106.

Summers, L. H. (1991). The scientific illusion in empirical macroeconomics. The Scandinavian Journal of Economics, 93(2):129-148.

Vines, D. and Wills, S. (2018). The rebuilding macroeconomic theory project: An analytical assessment. Oxford Review of Economic Policy, 34(1-2):1-42.

Woodford, M. (2008). How important is money in the conduct of monetary policy? Journal of Money, credit and Banking, 40(8):1561-1598.

Wulfsberg, F. (2016). Inflation and price adjustments: Micro evidence from Norwegian consumer prices 1975-2004. American Economic Journal: Macroeconomics, 8(3):175-94. 